SOCIAL SCIENCE RESEARCH

\author{
Antonio Guarino * \\ Steffen Huck ** \\ Thomas D. Jeitschko ***

\section{Can Fear Cause Economic Collapse? Insights from an Experimental Study}
* University College London (UCL)
** University College London (UCL)
*** Michigan State University

SP || $2004-05$

March 2004

ISSN Nr. $0722-6748$

Research Area

Markets and Political Economy

Research Unit

Market Processes and Governance
Forschungsschwerpunkt

Markt und politische Ökonomie

Abteilung

Marktprozesse und Steuerung 
Zitierweise/Citation:

Antonio Guarino, Steffen Huck, Thomas D. Jeitschko,

Can Fear Cause Economic Collapse? Insights from an Experimental Study, Discussion Paper SP II 2004 - 05, Wissenschaftszentrum Berlin, 2004.

Wissenschaftszentrum Berlin für Sozialforschung gGmbH,

Reichpietschufer 50, 10785 Berlin, Germany, Tel. (030) 25491 - 0

Internet: www.wz-berlin.de 


\section{Can Fear Cause Economic Collapse? Insights from an Experimental Study}

by Antonio Guarino, Steffen Huck and Thomas D. Jeitschko *

We study the behavior of experimental subjects who have to make a sequence of risky investment decisions in the presence of network externalities. Subjects follow a simple heuristic - investing after positive experiences and reducing their propensity to invest after a failure. This result contrasts with the theoretical findings of Jeitschko and Taylor (2001) in which even agents who have only good experiences eventually stop investing because they are afraid that others with worse experiences will quit. In theory, this "Bayesian fear" can trigger sudden economic collapse - even in the most efficient Bayesian equilibrium. In the experiment, subjects are surprisingly fearless of others' experiences, and simply follow their own experiences, thus averting a total collapse.

Keywords: Coordination, coordination avalanche, economic collapse, experimental economics, network externalities

JEL Classification: C7, C9, D8, E0, GO

\section{ZUSAMMENFASSUNG}

\section{Kann Angst zu einem Wirtschaftszusammenbruch führen? Erkenntnisse aus einer experimentellen Studie}

Wir untersuchen das Verhalten experimenteller Subjekte, die in Anwesenheit von Netzexternalitäten (externen Effekten) eine Reihe von riskanten Investitionsentscheidungen machen sollen. Die Subjekte folgen einer einfachen Heuristik - sie investieren nach positiven Erfahrungen, nach einem Misserfolg reduzieren sie ihre Investitionsneigung. Diese Resultate stehen im Gegensatz zu den theoretischen Befunden von Jeitschko und Taylor (2001), in welchen sogar die Agenten, die ausschließlich positive Erfahrungen gemacht haben, schließlich aufhören zu investieren, weil sie Angst haben, dass die anderen, mit schlechteren Erfahrungen, ausscheiden werden. Theoretisch kann diese "Bayesianische Angst" einen plötzlichen Wirtschaftszusammenbruch auslösen auch in dem effizientesten Bayesianischen Gleichgewicht. Im Experiment sind die Subjekte überraschend furchtlos bezüglich der Erfahrungen der anderen. Sie folgen einfach nur eigenen Erfahrungen und verhindern so den totalen Zusammenbruch.

\footnotetext{
* We wish to thank Dirk Engelmann, Wieland Müller, Hans Normann, Pedro Rey Biel, and Georg Weizsäcker for many helpful comments and suggestions. Financial support from the Leverhulme Trust and the ESRC via ELSE is gratefully acknowledged.
} 


\section{Introduction}

In his first inaugural speech, in March 1933, as the world was in the grip of the Great Depression, Franklin Delano Roosevelt told Americans "We have nothing to fear, but fear itself." Can we really consider fear causal for bad economic outcomes? In a recent paper, Thomas D. Jeitschko and Curtis R. Taylor (2001) suggested that this is the case: Fear can indeed generate an economic collapse in a world of perfectly rational agents.

Consider a situation in which agents can invest repeatedly in a risky project. The project can be good or bad, depending on the state of the world. The outcome of the project also depends on the decisions of other agents, as there are network externalities or complementarities in actions. Agents only observe the outcomes of their own investments and then decide whether to invest again and so forth. In such a situation, a global economic collapse - a "coordination avalanche" as Jeitschko and Taylor put it - can occur: Agents may be discouraged and stop investing even though they had only positive outcomes.

At a first glance this result appears counter-intuitive. But, in fact, it follows from a rather simple Bayesian logic: As time passes, agents have to consider the possibility that there are other agents who have bad experiences. After some bad experiences these agents will decide not to invest. Because these agents drop out, the positive externality is not big enough for agents who had just slightly better experiences than those with the worst experiences. These agents, therefore, will drop out as well, and so on. Jeitschko and Taylor show that this chain can go on in such a way that all agents simultaneously abandon the investment. The local discouragement propagates and triggers a coordination avalanche. Even if the state of the world is good (and all investment opportunities are profitable), the fear that other agents may abandon the project induces everyone to do so. Notice that this is not the result of a pure coordination failure. Indeed, the collapse of investment occurs in the Pareto-efficient equilibrium of the game. 
In addition to its obvious macro-economic implications, the coordination avalanche theory has many other interesting applications. Jeitschko and Taylor, for instance, show that the avalanche can explain organizational meltdowns: Agents may simultaneously abandon an efficient organization only because each one fears that his colleagues may do so. Similarly, the fear that other agents may upgrade their computers may induce a sudden and inefficient shift to a new program, in order to keep compatibility with friends and coworkers. In recent years it has also been argued that it is difficult to explain some financial crises by looking at the fundamentals of the economy and that, instead, they seem triggered just by panic. Given that network externalities are important in these markets, the avalanche theory can also be thought of as a possible cause of these crises.

In this paper we discuss some implications of the Jeitschko and Taylor model through an experimental study. In particular, we consider an environment in which features of a coordination avalanche are present in equilibrium, in order to ascertain whether these phenomena are observed in the laboratory. Is fear a determinant of a bad economic outcome in a laboratory market? Do subjects abandon a risky investment after observing only good outcomes?

The answer of our experimental study to both these questions is no. Subjects in the laboratory seem to follow a simple heuristic that is in stark contrast with the perfect Bayesian equilibrium solution of the game: They invest after they receive good outcomes. Once they have a bad experience, their propensity to invest drops, on average, from almost 100 percent to roughly 60 percent. While this behavior is not in line with individual payoff maximization (after failing, subjects should quit investing in order to maximize their payoffs and even after successes they should stop investing at a certain point), it provides a public good because of the network externality. Positive network externalities last longer than if subjects followed the equilibrium path and, consequently, sudden economic collapse is avoided. Because of this, the heuristic allows subjects to avoid "coordina- 
tion avalanches" and to earn payoffs similar to those in the Pareto-efficient equilibrium.

In Section 2, we describe the model and its Pareto-efficient equilibrium. In Section 3, we illustrate the experiment and the experimental design. In Section 4 we report our results. Section 5 concludes.

\section{Theory}

\subsection{The model}

We present a simplified version of the model proposed by Jeitschko and Taylor (2001). Consider an economy with a continuum of agents with mass normalized to 1 . In each period, $t=1,2, \ldots, T$, agents are randomly paired and called upon to play a simultaneous-move, two-by-two investment game, akin to a stochastic version of the classic stag-hunt game.

At the outset of each period each agent receives an endowment of $\omega$. This can either be consumed completely (strategy choice "NO"), in which case the agent's payoff is simply $\omega$ and the period effectively ends for the agent; or a portion $c(<\omega)$ of the endowment can be invested (strategy choice "INVEST").

In the case that the agent chooses "INVEST," his payoff depends on two things: the choice of the agent he is matched with; and a chance move by nature. If his partner chooses "NO," the investment of $c$ is forfeited and the agent obtains a payoff of $\omega-c$. If his partner chooses "INVEST," the payoff depends on a chance move by nature. Specifically, with probability $p$ the investment is a success, yielding a (net) payoff of $(\omega-c)+S$. Otherwise (with probability $1-p$ ), the investment fails, yielding a payoff of $\omega-c$.

Letting $m$ denote the measure of the population that invests; an agent's per-period expected payoff, $u(x)$, for strategy $x$, is given by

$$
\begin{aligned}
u(\mathrm{NO}) & =\omega, \quad \text { and } \\
u(\mathrm{INVEST}) & =(\omega-c)+m p S .
\end{aligned}
$$


Agents observe only their own payoffs, but not other agents' payoffs or strategy choices (i.e., $m$ ), nor nature's chance moves.

Provided that the success rate of investments, $p$, and the payout of successful investment, $S$, are sufficiently high compared to the cost of investing, $c$, (i.e., $p S>c$ ), the one-shot game has two symmetric pure strategy equilibria: with all playing "INVEST" $(m=1)$ Pareto-dominating the all play "NO" $(m=0)$ equilibrium. The one-shot game is then one of pure coordination.

Now suppose that while $\omega, c$, and $S$ are known values, there is uncertainty about the magnitude of the intrinsic success rate of investments, $p$. In particular, suppose that $p$ is fixed over time, but takes one of two possible values, $\underline{p}$ or $\bar{p}$, both initially equally likely.

Suppose further that $0 \leq \underline{p}<c / S<\bar{p} \leq 1$ so that investments are expected to be profitable in the good state, but not in the bad state; and $\mathbf{E}[p]:=(\underline{p}+\bar{p}) / 2>c / S$ so that initially investment is collectively rational.

Assume that all agents have the correct common prior, so the game is one of pure coordination - at least initially, at time $t=1$. Assume further that it is common knowledge that all agents tacitly coordinate on the good equilibrium in the first period of play. Then, nevertheless, in the first period some agents may experience failed investment outcomes while others do not. Those with successful investment outcomes will attach more weight to the likelihood that the value of the intrinsic success rate of investments is $\bar{p}$; those with failures find it more likely that it is $\underline{p}$.

As $\underline{p}<c / S$, if any positive mass of agents puts sufficiently strong weight on the state being bad, they will choose to play "NO," and complete coordination, in which $m=1$, can no longer be achieved.

All agents can determine after how many failed investment attempts a Bayesian agent, who assumes coordination amongst the population, will no longer invest. And at this point, in addition to updating beliefs about $p$, all agents must form beliefs about $m$. Thus, agents update their beliefs on the success rate of investments, and must also account for a (negative) network 
externality, namely how attrition affects the size of $m$.

As agents assess the decrease in $m$, they expect lower returns from investing. Consequently, it may be the case that agents with fairly optimistic beliefs regarding $p$ begin playing "NO," due to the imputed negative network externality caused by those who have become pessimistic about $p$.

A point may even come where agents with uniformly good experiences, i.e., those who have never had an investment fail, conjecture that there is sufficient attrition in the population to no longer warrant an investment. At this point, despite agents having different beliefs about the state of the world, the only action supportable in equilibrium is the one in which all play "NO" and $m=0$.

It is important to note that whether such a point is in fact reached is a function of prior beliefs and need not depend on the true state of the world. In fact, even if $p=\bar{p}=1$, this type of complete attrition may occur. This will be demonstrated in the parameterization chosen below.

\subsection{Parameterization and the Pareto-efficient perfect Bayesian equilibrium}

We turn now to illustrate the features of the model for the particular parameters that we chose for the experiment. Agents are repeatedly randomly matched for a total of 5 periods. At the beginning of each period they are newly endowed with $\omega=£ 1.70$. The cost of undertaking an investment is $c=£ 1.64$, and successful investments pay out $£ 2.00$ (per agent). There is no discounting.

In the bad state of the world, the success rate is $\underline{p}=0.8$, whereas in the good state is $\bar{p}=1$. Both states are ex ante equally likely.

We are interested in determining the longest string of playing "INVEST," assuming complete coordination. The assumption of complete coordination postulates that an agent plays "INVEST" whenever all others with equivalent or more optimistic beliefs do so. That is, we are looking for a Pareto-efficient perfect Bayesian equilibrium. Since $\mathbf{E}[p]=0.9$, 
if all agents invest in the first period, they receive an expected payoff of $u(\operatorname{INVEST})=(£ 1.70-£ 1.64)+(.9)(1)(£ 2.00)=£ 1.86$, which is greater than the $£ 1.70$ obtained from playing "NO," so all agents invest in the first period.

Under this assumption, if an agent experiences a failure in the first period, the intrinsic success rate of investments is revealed to this agent to be $p=\underline{p}$ (because there are no failures with $\bar{p}=1$ ). Thus, agents with a failure in Period 1 will have full information and, as is easily verified, will cease to invest - regardless of the number of people in the population that invest.

Agents who experience a success will not know the true state of the world, but will increase the weight they place on the state being the good state. In particular, the Bayesian estimate of the state of the world being the good one after a success in the first period (when $m=1$ ) is $5 / 9$.

As they cannot be sure that no-one experienced failures, however, they will anticipate that there may be some agents who quit investing in the second period. Hence, assuming that all agents with a success in the first period continue investing, an agent with a first period success expects to have again a success for sure in the second period when investing with probability $5 / 9$.

However, with the complementary probability of $4 / 9$, he expects an effective success rate of only 64 percent (the probability of being matched with someone who invests and experiencing a success with that person, when the true $p$ is $\underline{p}=0.8)$. This yields a composite expected success rate $(\mathbf{E}[p m] \mid$ success $)$ of 0.84 and hence $u($ INVEST $\mid$ success $)=£ 1.74$. Since $£ 1.74>£ 1.70=u(\mathrm{NO})$, all agents that experience a success in the first period should also invest in the second period.

Agents who in the second period experience a failure also know that the true state of the world is the bad state, for either they were matched with someone who invested, yet their investment failed; or they were match with someone who had previously observed that the state was bad, and hence chose to play "NO." 
On the other hand, those with a success in the second period will be even more optimistic that the state is the good state. These agents, however, must now account for the fact that if the state is actually bad, then attrition has spread through two periods of play.

Bayesian updating now yields $u($ INVEST $\mid 2$ successes $) \approx £ 1.68$. So, despite being rather optimistic about the state of the world after two consecutive successes, it is no longer worth investing, because in the event that the state is bad, attrition will have spread so far as to make investments very unlikely to pay off.

This yields the following Proposition:

Proposition (Pareto Efficient Perfect Bayesian Equilibrium) The strategy profile that specifies that all agents play "INVEST" until they have either experienced a failure in the previous period or have reached the third period, and thereafter play "NO," constitutes a Pareto efficient perfect Bayesian equilibrium (PEPBE).

An implication of the PEPBE of the Proposition is that all agents play "NO" in Periods 3 through 5, regardless of their experiences in the first two periods, and regardless of the true value of $p .^{1}$

\section{Experimental design and procedures}

\subsection{The experiment}

We conducted the experiment in the laboratory of the ELSE Centre at University College London. We recruited subjects from the College's undergraduate population across all disciplines. They had no previous experience

\footnotetext{
${ }^{1}$ The PEPBE of the Proposition is not unique. Any prescription that involves all playing "NO" in any three of the five periods, and prescribes maximal cooperation (in the history-dependent sense above) in the other two, is also a PEPBE. We do not consider multiple PEPBE a concern for the questions of interest as the Proposition gives a very clear focal point. Nevertheless, we do address this issue in one of the treatments.
} 
with this or similar experiments. For each session of the experiment we recruited 8 students. In total, we recruited 80 subjects to run 10 sessions (five sessions for each of two treatments).

At the beginning of the sessions, we handed out written instructions (see appendix) to all subjects. Subjects were made aware that they all had the same instructions. Afterwards, subjects saw a simulated run of the experiment on their computer screens. This helped them to understand all the steps that they had to go through during the experiment, the timing of the decisions that they had to take, and the information that they would have received after each decision. Finally, we asked if there were any clarifying questions. No subject had problems in understanding the experimental procedures.

Each session consisted of a series of 15 rounds. Each round was a sequential 5-period game as described in the previous section. Let us illustrate the procedures for each round. At the beginning of the round the software chose, with equal probability of 0.5 , whether the investment that subjects were going to make would be successful with probability 1 or with probability 0.8 only. $^{2}$ We explained this to students by writing in the instructions that the computer would randomly choose, by "flipping a coin," between two urns, Urn 1 or Urn 2. Urn 1 contained only green balls and Urn 2 contained 80 green and 20 red balls. The chosen urn, i.e., the chosen probability distribution, was used for all participants and for all periods in this round. Of course, subjects were not informed of which distribution had been selected.

After the probability distribution (urn) was chosen, subjects had to decide for five times in sequence whether or not to invest in a project. For each decision in the sequence, subjects had to act simultaneously, i.e., not knowing what other subjects had decided to do. After all subjects had made their first decision, the computer drew for each subject who had invested a

\footnotetext{
${ }^{2}$ Our choice of $\bar{p}=1$ for the good state of the world has two advantages. First, it makes the updating process easy. Second, given that we are primarely interested in the behavior of agents who had good experiences, it maximizes the number of interesting observations in our experiment.
} 
ball from the chosen urn to decide whether the investment was successful or not. A green ball meant that the investment was successful, and a red ball that it was a failure. The draws were independent, i.e., keeping the urn metaphor, balls were drawn with replacement.

After all participants had made their first decision, they were randomly matched one to another by the software. There was an equal probability for each subject of being matched with anyone of the other seven participants. The matching co-determined the payoff of subjects who had decided to invest. A subject would earn money by investing under two conditions: that the computer had drawn a green ball; and - at the same time - that the subject she was matched to had decided to invest as well.

After all 8 subjects had made their decision, they were informed of their payoff. We gave subjects $£ 1.70$ for each of the five decisions. They could use that money to pay for the cost of the investment or just keep it, if they decided not to invest. If they decided to invest, they had to pay a cost of $£ 1.64$. If the investment was successful and the match invested too, a subject earned $£ 2$; and nothing otherwise. Therefore, in the case of an investment, the subject had two possible payoffs: $£ 1.70-£ 1.64+£ 2=£ 2.06$ in the first case; and $£ 1.70-£ 1.64+£ 0=£ 0.06$ in the other.

Agents were informed only of their payoff, and nothing else. Therefore, a subject could not distinguish whether the low payoff was due to bad luck, i.e., the red color of the ball, or to the decision of the other participant. After learning about their payoffs, participants had to make their second investment decision. They knew that the same distribution (urn) previously chosen would be used again, but that new balls would be drawn for everyone investing.

Subjects had to repeat this decision for 5 periods in a round. After the fifth period of the round, each participant could see on the screen what urn the computer had chosen in this round, the color of the balls that he was assigned for each investment decision, and the decisions of the other participants he was matched with in each of the five periods. The computer 
also showed the total payoff for that round, i.e., the sum of the payoffs obtained in each period.

After the first round was over, we repeated the same procedure for the second round: At the beginning the computer chose again one of the two distributions and students made their five decisions. The same for a total of 15 rounds.

\subsection{Treatments}

We ran two treatments for this experiment. The procedures for the first treatment ("Treatment $A$," from now on) were as described in the previous section. In addition to that, we asked subjects to write down their beliefs, i.e., what their expected value of the investment was. In particular, in each period, we asked students how much, at most, they would have paid for the investment. They could choose on the screen a number between $£ 0$ and $£ 2$ with ticks of 1 penny. We did so in order to understand how beliefs evolved over time. Notice, in fact, that the decision of a subject to invest (not to invest) only tells us that he thought the investment was worth more (less) than its cost $(£ 1.64)$ but it does not reveal the precise value he attaches to the investment. We did not provide monetary incentives for this task as the true value of the investment depends on both, a subject's (posterior) belief about the chosen urn and his expectation about others' investment behavior. As we cannot control for the latter, it is impossible to rely on incentive mechanisms for this task. ${ }^{3}$

In the other treatment ("Treatment $B$ ") we included a feature that would help subjects to coordinate on the Pareto optimal equilibrium. Remember that our primary interest was studying behavior when there is full coordination. We were interested in observing the behavior of subjects after some successful experiences. After all, this is a key implication of the the-

\footnotetext{
${ }^{3}$ Interestingly and somewhat surprisingly, Joep Sonnemans and Theo Offerman (2001) show for a task where correct beliefs can be specified that subjects' actual beliefs can be as accurately elicited without incentives as with a quadratic scoring rule.
} 
oretical model: agents may quit investing because of fear that others do so (despite having made only positive experiences on their own). If no one invests all the times, there is no possibility of such observations. Therefore, to help subjects to coordinate on the PEPBE described in the Proposition, we forced subjects in Treatment $B$ to invest in Period 1. We explained to them that to invest in Period 1 was the right thing to do if everyone did so, and disabled the "don't invest" button for that period. Therefore, in this treatment, subjects actually had to make only four decisions, from the $2^{\text {nd }}$ to the $5^{\text {th }}$ period. Furthermore, we told them that whenever they decided not to invest, they would not have the opportunity to invest again in later periods of that round. ${ }^{4}$ We imposed this constraint to avoid early coordination failures. In other words, we made the decision of not investing being definitive, so that subjects would think seriously whether it was the right decision or not. ${ }^{5}$

\section{Results}

We start by describing the aggregate investment decisions over time in Treatment $A$. Table 1 shows the proportion of investment decisions for all five periods averaged over all rounds. These proportions are compared with those that would occur in the Pareto-optimal equilibrium, given the realization of the chance moves, i.e., the frequency of the two urns.

Table 1 reveals two striking features of the data - departing from the Pareto-efficient equilibrium investment rates. First, there is a tremendous amount of coordination failure. Less than half of the decisions in the first period are investments. Second, there is no sharp drop in investment rates

\footnotetext{
${ }^{4}$ This eliminated all PEPBE outcomes, except for the one described in the Proposition, so the the PEPBE of the game was unique.

${ }^{5}$ By changing two aspects from Treatment $A$ to Treatment $B$, we will not be able to assess the individual effects of a) forcing subjects to invest in the first period and b) making non-investment definitive. We are simply not interested in studying the isolated consequences of these specific design features. All we wanted to achieve is to design a treatment where coordination failure is not an issue. And as we shall see below, Treatment $B$ was successful in achieving this.
} 


\begin{tabular}{cccccc}
\hline \hline Aggregate Data A & Period 1 & Period 2 & Period 3 & Period 4 & Period 5 \\
\hline $\begin{array}{c}\text { PEPBE } \\
\text { Investment Rates }\end{array}$ & 1 & 0.91 & 0 & 0 & 0 \\
$\quad \begin{array}{c}\text { Observed } \\
\text { Investment Rates }\end{array}$ & 0.44 & 0.38 & 0.33 & 0.29 & 0.28 \\
Observations & 600 & 600 & 600 & 600 & 600 \\
\hline
\end{tabular}

Table 1: PEPBE and observed investment rates in Treatment A.

\begin{tabular}{ccccc}
\hline \hline Only Successes A & Period 2 & Period 3 & Period 4 & Period 5 \\
\hline $\begin{array}{c}\text { PEPBE } \\
\text { Investment Rates }\end{array}$ & 1 & 0 & N/A & N/A \\
$\quad \begin{array}{c}\text { Observed } \\
\text { Investment Rates }\end{array}$ & 0.94 & 0.93 & 0.94 & 1.00 \\
Observations & 134 & 74 & 49 & 33 \\
\hline
\end{tabular}

Table 2: PEPBE and observed investment rates for subjects who have only experienced successes in Treatment A.

in Period 3, in which even optimistic subjects should stop investing. In fact, the decline in investment rates is slow and steady over all five periods.

To explain this pattern we looked at subjects' decisions after histories of successful or unsuccessful investments. Table 2 shows the investment rates of subjects who had only experienced successes in the previous periods. Table 3 shows the same for subjects who had experienced a failure in the previous period. From these two tables, a very simple pattern emerges: Subjects keep investing as long as they are successful. Once they experience a failure, their propensity to invest drops - on average to less than 60 percent.

This behavioral pattern is also reflected in the belief data that we elicited.

In Figure 1, we plot the PEPBE (downward sloping curve) and reported (upward sloping curve) beliefs for subjects who were always successful when investing in the previous periods. In the PEPBE the expected value of the investment decreases over time. In Period 3 it becomes lower than the cost and, therefore, from Period 3 on, in equilibrium, agents attach a value of 0 to the investment, as all agents decide not to invest. The reported 


\begin{tabular}{ccccc}
\hline \hline Previous Failure A & Period 2 & Period 3 & Period 4 & Period 5 \\
\hline $\begin{array}{c}\text { PEPBE } \\
\text { Investment Rates }\end{array}$ & 0 & 0 & N/A & N/A \\
$\begin{array}{c}\text { Observed } \\
\text { Investment Rates } \\
\text { Observations }\end{array}$ & 0.58 & 0.57 & 0.58 & 0.60 \\
\hline
\end{tabular}

Table 3: PEPBE and observed investment rates for subjects who have experienced a failure in the previous period in Treatment A.

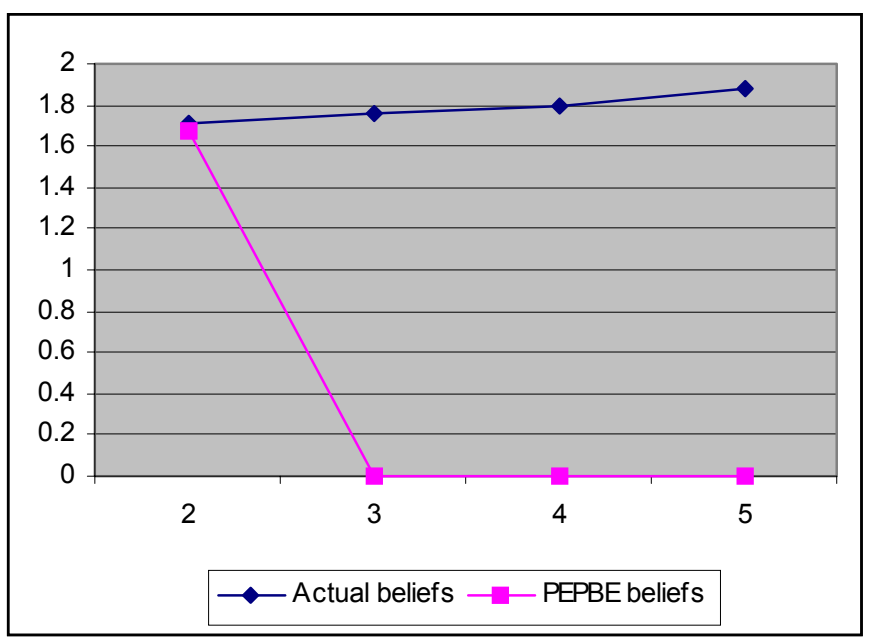

Figure 1: PEPBE and observed average beliefs about the expected value of an investment, given a history that consists of successes only. 


\begin{tabular}{cccccc}
\hline \hline Aggregate Data B & Period 1 & Period 2 & Period 3 & Period 4 & Period 5 \\
\hline PEPBE & 1 & .90 & 0 & 0 & 0 \\
Investment Rates & & & & & \\
$\quad$ Observed & 1 & 0.94 & 0.87 & 0.77 & 0.66 \\
Investment Rates & 600 & 600 & 600 & 600 & 600 \\
$N$ & &
\end{tabular}

Table 4: PEPBE and observed investment rates in Treatment B.

beliefs are in stark contrast to this. In Period 2 subjects on average valued the investment at $£ 1.7$, almost identical to the full coordination value of $£ 1.68$. After experiencing successes, however, subjects are more and more optimistic, becoming increasingly confident that the true state is the good one and that other subjects would keep investing, too.

A pattern of increasing confidence might be expected if there is initial uncertainty about the level of coordination in the population, yielding lower expected returns at first, and then subsequent increasing confidence as fears of lacking coordination are dispelled. Such a sequence of beliefs, however, would be bounded above by the beliefs from the PEPBE. And as reported beliefs rise above those of the PEPBE, it is clear that subjects are updating in the wrong direction.

While these data draw a rather coherent picture of subjects' behavior in Treatment $A$, they are not ideally suited for comparison with the PEPBE given in the Proposition. There is simply too much coordination failure early on. In a second treatment, we utilized devices discussed above to help subjects to coordinate, in particular, making subjects invest in the first period.

Table 4 shows aggregate investment rates over time for this treatment. Tables 5 and 6 show the investment rates for subjects who had only successes and for subjects who experienced a failure in the preceding period.

Several observations are in order. First, the coordination in the first period has a tremendous effect for the later periods. Once coordinated, subjects keep coordinating. This result is similar to earlier findings on the 


\begin{tabular}{ccccc}
\hline \hline Only Successes B & Period 2 & Period 3 & Period 4 & Period 5 \\
\hline PEPBE & 1 & 0 & N/A & N/A \\
Investment Rates & & & & \\
$\quad$ Observed & .94 & .97 & .98 & .94 \\
Investment Rates & & 440 & 361 & 290 \\
Observations & 540 & 44 \\
\hline
\end{tabular}

Table 5: PEPBE and observed investment rates for subjects who have only experienced successes in Treatment B.

\begin{tabular}{ccccc}
\hline \hline Previous Failure B & Period 2 & Period 3 & Period 4 & Period 5 \\
\hline $\begin{array}{c}\text { PEPBE } \\
\text { Investment Rates }\end{array}$ & 0 & 0 & N/A & N/A \\
$\begin{array}{c}\text { Observed } \\
\text { Investment Rates } \\
\text { Observations }\end{array}$ & 0.87 & 0.64 & 0.53 & 0.60 \\
\hline
\end{tabular}

Table 6: PEPBE and observed investment rates for subjects who have experienced a failure in the previous period in Treatment B.

importance of the first few periods for the entire trajectory of play (see, for example, John B. van Huyck, Raymond C. Battalio, and Richard O. Beil 1991, or van Huyck, Joseph B. Cook, and Battalio 1997).

Second, the decline in investment rates mirrors the decline observed in Treatment $A$ in that it is steady and slow. Moreover, there is no sudden drop-off in the investment rate in Period 3. Third, subjects seem to apply the same decision rules as in Treatment $A$. They keep investing as long as investments are successful. Once discouraged, the investment rate drops with some inertia to almost the same numbers as in Treatment $A$.

The data that we have described so far refer to the entire experiment and one may wonder whether there is any time trend in the data, perhaps toward the PEPBE. Analyzing the last few rounds separately, however, we see that behavior is remarkably stable over time. Subjects stick to their simple heuristic throughout the experiment. In Tables 7 and 8 we report the investment decisions in the last five rounds of the fifteen-round sessions. 


\begin{tabular}{ccccc}
\hline \hline $\begin{array}{c}\text { Only Successes } \\
\text { (last five rounds) }\end{array}$ & Period 2 & Period 3 & Period 4 & Period 5 \\
\hline $\begin{array}{c}\text { Observed } \\
\text { Investment Rates A } \\
\begin{array}{c}\text { Observed } \\
\text { Investment Rates B }\end{array}\end{array}$ & 0.89 & 0.95 & 1 & 1 \\
\hline
\end{tabular}

Table 7: Observed investment rates for subjects who have only experienced successes in the last five rounds of the two treatments.

\begin{tabular}{ccccc}
\hline \hline $\begin{array}{c}\text { Previous Failure } \\
\text { (last five rounds) }\end{array}$ & Period 2 & Period 3 & Period 4 & Period 5 \\
\hline $\begin{array}{c}\text { Observed } \\
\text { Investment Rates A }\end{array}$ & 0.32 & 0.61 & 0.80 & 0.67 \\
$\begin{array}{c}\text { Observed } \\
\text { Investment Rates B }\end{array}$ & 0.86 & 0.60 & 0.44 & 0.58 \\
\hline
\end{tabular}

Table 8: Observed investment rates for subjects who have only experienced successes in the last five rounds of the two treatments.

Even at the end of the experiment, subjects in both treatments invested almost always after having experienced successes; and significantly reduced their propensity to invest after a failure.

All the previous analysis refers to data aggregated over all participants. To shed more light on subjects' behavior, we also looked at individual decisions. Table 9 illustrates how subjects reacted to a successful investment. In particular, it divides subjects according to their different propensities to invest after a success. Behavior is remarkably homogeneous: Almost $70 \%$ of subjects in Treatment $A$ and more than $80 \%$ in Treatment $B$ re-invest in more than $80 \%$ of all cases after a success. Table 10 shows how subjects reacted to failures. Behavior here is clearly more heterogeneous. While there is hardly anybody with an investment rate of less than $20 \%$ after a failure, the distribution of investment rates above $20 \%$ is almost uniform - with a slight bias toward more pessimistic behavior in Treatment $A$ and toward more optimistic behavior in Treatment $B$.

In all, the data from the two treatments draw a clear picture of subjects' 


\begin{tabular}{ccc}
\hline \hline $\begin{array}{c}\text { Percentage of Investments } \\
\text { after a Success }\end{array}$ & Treatment A & Treatment B \\
\hline$[0,20)$ & 0 & 0.025 \\
{$[20,40)$} & 0.065 & 0.025 \\
{$[40,60)$} & 0.16 & 0.025 \\
{$[60,80)$} & 0.097 & 0.075 \\
{$[80,100]$} & 0.68 & 0.85 \\
\hline
\end{tabular}

Table 9: Individual decisions: subjects are divided according to the percentage of times in which they invested after a success in the previous period.

\begin{tabular}{ccc}
\hline \hline $\begin{array}{c}\text { Percentage of Investments } \\
\text { after a Failure }\end{array}$ & Treatment A & Treatment B \\
\hline$[0,20)$ & 0.09 & 0.075 \\
{$[20,40)$} & 0.33 & 0.15 \\
{$[40,60)$} & 0.18 & 0.175 \\
{$[60,80)$} & 0.21 & 0.2 \\
{$[80,100]$} & 0.18 & 0.4 \\
\hline
\end{tabular}

Table 10: Individual decisions: subjects are divided according to the percentage of times in which they invested after a failure in the previous period.

behavior. After a success, they all keep investing - which is quite at odds with the Pareto efficient equilibrium. After a failure, they reduce their propensity to invest. Some subjects do this very drastically, while others reduce their investment rates in a more moderate manner. Together, by relying on such simple backward-looking heuristics, subjects avoid economic collapse. It is worthwhile to note that by investing more than they should, subjects provide a substantial public good for all the others because of the rather big externalities of investments. As a consequence of this, the subjects in Treatment $B$ (where there is practically no coordination failure) earn almost as much as they would have in the PEPBE (£8.57 versus £8.67).

Basically, it is subjects' inability to apply Bayesian equilibrium reasoning that "protects" them from experiencing a collapse. Subjects seem unable to put themselves in others' shoes, to imagine that others might have had a different past than they themselves. This ignorance appears quite similar to 
what has been observed in some experiments on "informational cascades" (as proposed in the seminal contributions by Abhijit Banerjee 1992, and Sushil Bikhchandani, David Hirshleifer, and Ivo Welch 1992). Experimental studies on cascades have sometimes found support for the Bayesian equilibrium prediction and sometimes not. Recent evidence in a paper by Dorothea Kübler and Georg Weizsäcker (2003) suggests that the same behavioral rule can explain both, the theory's successes and its failures. The key feature of the behavioral rule Kübler and Weizsäcker identify is that subjects basically fail to understand that others whom they observe and from whom they learn have also learned from others whom they, in turn, had observed. Put differently, subjects do extract information from their predecessors' actions, but they do not take into account that their predecessors did the same. A similar failure of understanding the experience and reasoning of others also causes the discrepancy between equilibrium and observed play in our experiment: Subjects who were successful appear to have difficulties to imagine that others might have experienced failures.

\section{Conclusions}

In Jeitschko and Taylor's model sudden economic collapse can result from pure "fear." Even in a booming economy where all agents experienced good returns on all investments all the time a collapse can occur. Agents may quit investing not only because of their own bad experiences but also because they are afraid that others might have had bad experiences or even because they are afraid that others are afraid that others may have had bad experiences. And so on - even if nobody actually had a bad experience. In that sense it is "fear itself" (without any fundamentals being bad) that can induce an economic meltdown in Jeitschko and Taylor's analysis.

In this paper we have investigated whether such "Bayesian fear" can be observed in the laboratory. The answer is that it is not. Subjects are persistently optimistic as long as their own experiences are good. Jeitschko and 
Taylor point out in the conclusion to their paper that anything that increases the population's confidence may help in averting a complete breakdown in investment. In our experiment, it is subjects' "blind" optimism that indeed raises confidence and does avert economic breakdown. And while such behavior is not individually rational, averting breakdown is on average beneficial to the population, as in expectation investments are profitable. The heuristics described in this paper do exactly this. Continued investment, sometimes even after bad news, slows down attrition and thus raises the confidence of continued investment activity and, ultimately, collective payoffs. That is, the individual reduction in payoffs experienced in using an optimistic heuristic compared to equilibrium play can be fully compensated by the positive network externality of continued play so that the population as a whole does quite well.

\section{References}

[1] Banerjee, Abhijit. "A Simple Model of Herd Behavior," Quarterly Journal of Economics, 1992, 107 (3), 787-818.

[2] Bikhchandani, Sushil, David Hirshleifer, and Ivo Welch. "A Theory of Fads, Fashion, Custom and Cultural Change As Informational Cascades," Journal of Political Economy, 1992, 100 (5), 992-1027.

[3] Jeitschko, Thomas D., and Curtis Taylor. "Local Discouragement and Global Collapse: A Theory of Coordination Avalanches," American Economic Review, 2001, 91 (1), 208-224.

[4] Kübler, Dorothea, and Georg Weizsäcker. "Limited Depth of Reasoning and Failure of Cascade Formation in the Laboratory," Review of Economic Studies, 2003, forthcoming.

[5] Sonnemans, Joep, and Theo Offerman. "Is the Quadratic Scoring Rule Really Incentive Compatible?," mimeo, 2001, University of Amsterdam. 
[6] van Huyck, John B., Raymond C. Battalio, and Richard O. Beil. "Strategic Uncertainty, Equilibrium Selection, and Coordination Failure in Average Opinion Games," Quarterly Journal of Economics, 1991, 106 (3), 885-910.

[7] van Huyck, John B., Joseph P. Cook, and Raymond C. Battalio. "Adaptive Behavior and Coordination Failure," Journal of Economic Behavior and Organization, 1997, 32 (4), 483-503. 


\section{Appendix: Instructions for Treatment A}

Welcome to our experiment!

Please be quiet during the entire experiment. Do not talk to your neighbours and do not try to look at their screens. Simply concentrate on what you have to do.

If you have a question, please raise your hand. We will come to you and answer it privately.

You are participating in an economics experiment in which you interact with seven other participants for 15 rounds. Depending on your choices, the other participants' choices and some luck you can earn a considerable amount of money. You will receive the money immediately after the experiment. Notice that all participants have the same instructions.

\section{The experiment}

\section{What you have to do}

The experiment consists of a series of 15 rounds. In each round you have to make five decisions. More specifically, you will be asked 5 times in sequence if you want to make an investment or not. If you make an investment, you will have to pay a cost of $£ 1.64$. The investment can be either successful or not. If it is successful, you can earn $£ 2$. After each investment decision, you will be informed about your payoff.

What determines whether the investment is successful or not

Imagine two urns. Urn 1 contains only green balls. Urn 2 contains 80 green and 20 red balls. At the beginning of each round the computer will randomly choose one of the two urns by tossing a coin. That is, both urns are equally likely to be chosen. However, we will not tell you which urn the computer has chosen!

Once an urn has been chosen for a round this urn will be used to determine the success of all investment decisions within this round. (Remember 
there are 5 such decisions in each round.) After each investment decision the computer will randomly draw one ball of the chosen urn for each participant. If you are assigned a green ball, your investment is successful, if it is red it is unsuccessful.

Notice that if the computer initially chooses urn 1, the investment will always be successful. On the other hand, if it chooses urn 2, the investment will, on average, be only successful 80 times out of 100 . Notice that there will be separate draws for each of your investment decisions and for each participant. That is, it is possible that an investment is successful for you and unsuccessful for another participant or vice versa.

\section{How do you pay for an investment?}

We give you $£ 1.70$ each time you have an investment opportunity. You may use this money to pay for the cost of the investment or you can just keep it if you decide not to invest.

What do you earn if you decide to invest?

If the investment is unsuccessful, its value is zero - regardless of what other subjects decide to do. Therefore, in this case, if you decided to invest, you lose $£ 1.64$ from the $£ 1.70$ you received from us. And you keep 6 pence.

If, on the contrary, the investment is successful, its value depends on the decisions of other subjects. After you have made your decision (invest or not) the computer will randomly match you with one of the other 7 subjects in the experiment. If this subject has decided to invest too, then you will receive $£ 2$. But if the other participant has decided not to invest, you will receive nothing. Therefore, in the former case your total payoff from this investment decision is what you have kept from the money we gave you (1.70 $-1.64)=6$ pence plus the pound you get from the successful investment. So, your total would be $£ 2.06$. In the latter case (where you have been matched with somebody who didn't invest) your payoff is $(1.70-1.64)+0=6$ 
pence. In other words, you will earn money by investing if the investment is successful for you and if the other participant matched with you has also decided to invest. Notice that although you can lose $£ 1.64$ by making an investment, your payoff for each investment will never be negative, as we give you $£ 1.70$ for each investment opportunity.

What do you earn if you decide not to invest?

If you decide not to invest, you will neither earn nor lose anything. You will just keep your $£ 1.70$. 
Procedures for each round

Remember that the experiment is organized into different rounds and that within each round you will have to make five investment decisions. So, let us summarize what happens within each round.

1) At the beginning of each round the computer randomly chooses one of the two urns, urn 1 or urn 2. The chosen urn will be used for all participants and all investment decisions in this particular round. But you will not be told which urn has been chosen.

2) Now you make your first decision: either invest or not.

3) If you have invested in 2), the computer draws a ball from the urn that was chosen in stage 1). The ball is drawn and then replaced, so that the total number of balls in the urn is always the same. The colour of the ball that was chosen for you determines whether your investment is successful or not. If it is green: success; if red: failure.

4) You will be randomly matched with another participant. If you haven't invested this is irrelevant for you. If you have invested and if your investment was successful in 3), your payoff depends on whether the other participant you have been matched with has also invested. If he has, you earn $£ 2$, if he hasn't you get nothing.

5) You will be informed about what has happened to your investment, i.e., about your payoff.

6) Now you make your second investment decision. Notice that the same urn that has determined your success previously will be used again. But a new ball will be drawn from that urn.

In other words, from 6) onwards everything is the same as from 2) on. This will be repeated 5 times. Your total payoff from the 5 decisions is just the sum of all payoffs you earned for each decision.

Once the first round is over, you will be informed of what urn the computer chose, the colour of the balls that it assigned to you, the decisions of the other participants that you were matched with and your payoff. Then, 
we will repeat the same procedure for the second round at the beginning of which the computer will choose again one of the two urns. And we will repeat the same procedures for the whole sequence of 5 investment decisions.

\section{One more question}

Whenever you have to decide whether to invest or not, we will also ask you another question: How much, at most, would you pay for the investment?

You know that the true cost of the investment is £1.64. Therefore, whenever you decide to invest, it's clear that you think the investment is worth an amount bigger than $£ 1.64$. What is this amount? That is, up to which cost would you be willing to pay for the investment? Similarly, whenever you decide not to invest, clearly you believe that the investment is worth an amount lower than $£ 1.64$. Again we ask you what this amount is. What is the highest cost for which you would be willing to invest?

Note that if you are successful the investment is worth $£ 2$, as this is the amount that we pay you. So if you were sure of obtaining success, clearly the investment would always be worth $£ 2$. On the other hand, if you were sure of being unsuccessful, then clearly the investment would be worth 0 , as in case of failure we pay you nothing. Therefore, the true value of the investment cannot be more than $£ 2$ and cannot be less than $£ 0$. Given that you do not know with certainty what the true situation is, the value of the investment has to be between 0 and 2. For this reason, on your screen you can select any number between $£ 0.00$ and $£ 2.00$.

\section{Examples of per round payoff}

\section{Example 1}

Suppose that for this round the computer has chosen urn 1. Therefore all balls are green. Suppose you make the following decisions:

INVEST, INVEST, INVEST, NO, NO 
Suppose, finally, that in the first two times you are matched with someone who invested, but in the third you are matched with someone who did not invest. Your payoffs would be:

$206+206+6+170+170=758$.

In this round, you earn money with the first 2 investments but you lose money with the third, despite all balls were green, because your match decided not to invest. The fourth and fifth times you just kept your 1.70 pence.

\section{Example 2}

Suppose for this round the computer has chosen urn 2. Therefore 80 out of 100 balls are green. Suppose you make the following decisions:

\section{INVEST, INVEST, INVEST, INVEST, NO}

Suppose, finally, that you received a green ball in the first 3 cases but not in the fourth. Suppose, finally, that you were always matched with someone who invested. Your payoffs would be:

$206+206+206+6+170=794$.

In this round, you earn money with the first 3 investments but you loose money with the fourth, because you got the red ball, i.e., your investment was not successful. The fifth time you just kept your 1.70 pence.

\section{Final payment}

For the simple fact that you showed up in time for the experiment you earn $£ 4$. The rest of the payment depends on how you perform. The computer will randomly choose one round out of the first 5 rounds, one among the 6 th through the 10th and one among the 11th though the 15th. Your payment will depend on how you performed in the selected rounds. We will sum up your payoffs in these three rounds and divide the sum by 3 . Your final payment will be equal to this amount plus the $£ 4$ for showing up. 